\title{
Epidemiological, clinical and laboratory profile of glucose-6-phosphate dehydrogenase deficiency in the middle and north of Iraq: a comparative study
}

M.D. Al-Mendalawi ${ }^{1}$

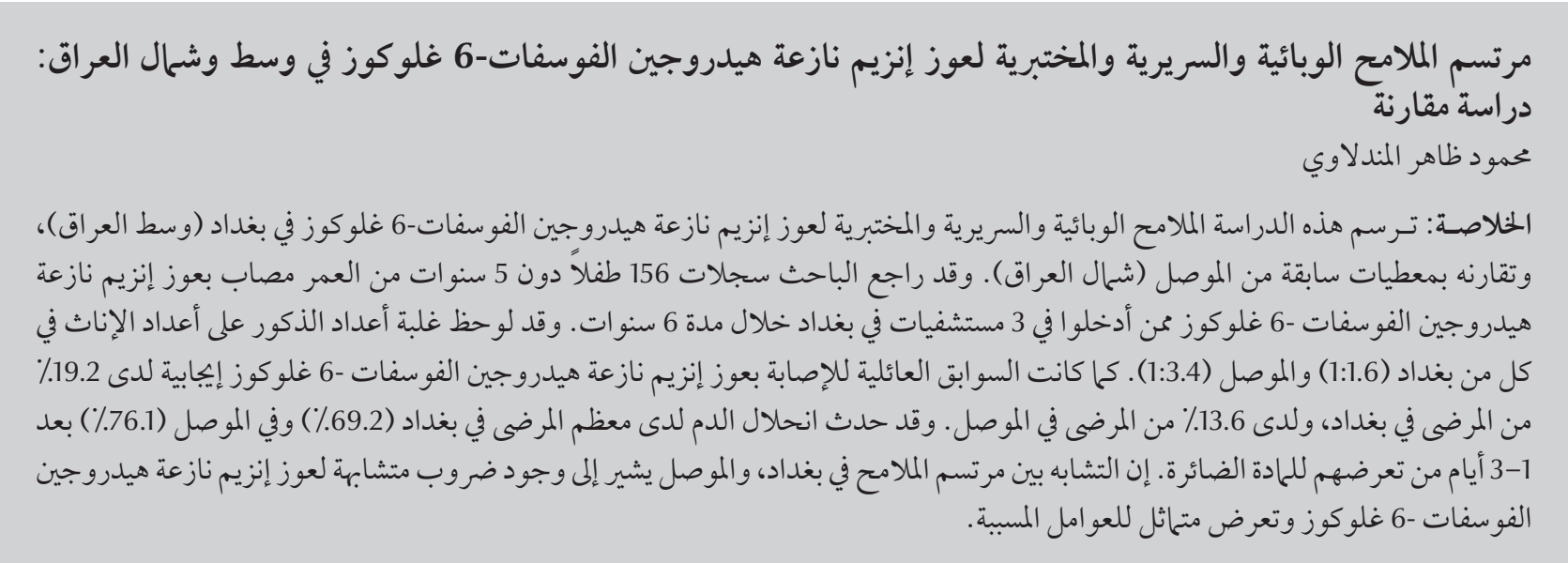

ABSTRACT This study determined the epidemiological, clinical and laboratory profile of glucose-6-phosphate dehydrogenase (G6PD) deficiency in Baghdad (central Iraq) and compared it with previous data from Mosul (northern Iraq). We reviewed the records of 156 under-5-year-olds with G6PD deficiency admitted to 3 hospitals in Baghdad over a 6-year period. A preponderance of males was noted in both Baghdad and Mosul (1.6:1 and 3.4:1 respectively). Family history of G6PD deficiency was positive in 19.2\% of patients in Baghdad and 13.6\% in Mosul. A majority of patients in Baghdad (69.2\%) and Mosul (76.1\%) showed haemolysis within 1-3 days of exposure to noxious agents. Similarities in the profiles from Baghdad and Mosul suggest that there are similar G6PD variants and similar exposure to precipitating agents.

Étude comparative du profil épidémiologique, clinique et biologique du déficit en glucose-6-phosphate déshydrogénase au nord et au centre de l'Iraq

RÉSUMÉ La présente étude a permis de déterminer le profil épidémiologique, clinique et biologique de la carence en glucose-6-phosphate déshydrogénase (G6PD) à Bagdad (centre de I'Iraq) et de le comparer avec des données antérieures recueillies à Mossoul (nord de l'Iraq). Nous avons examiné les dossiers de 156 enfants âgés de moins de 5 ans qui présentaient une carence en G6PD, hospitalisés dans trois hopitaux de Bagdad sur une période de six ans. Une prépondérance masculine a été constatée aussi bien à Bagdad qu'à Mossoul (1,6 garçon pour 1 fille et 3,4 garcons pour 1 fille respectivement). Des antécédents familiaux de cette maladie ont été observés chez 19,2 \% des patients à Bagdad et 13,6 \% de ceux de Mossoul. Dans les deux villes, la majorité des patients présentaient une hémolyse un à trois jours après une exposition à des agents nocifs (69,2 \% à Bagdad et à 76,1 \% à Mossoul). Des analogies entre les profils de Bagdad et ceux de Mossoul laissent penser qu'il existe des variants similaires de la G6PD et une exposition semblable à des facteurs déclenchants. 


\section{Introduction}

A functional deficiency of glucose-6phosphate dehydrogenase (G6PD) which oxidizes glucose-6-phosphate to 6-phosphogluconolactone in the pentose-monophosphate shunt with formation of reduced nicotinamide adenine dinucleotide phosphate (NADPH) - leads to oxidant-induced red-blood cell destruction [1]. It is the most common enzymopathy in the world and it has been estimated that more than 200 million people throughout the world are G6PD deficient. This genetic defect shows sex-linked inheritance and a marked heterogeneity. More than 300 abnormal variants with deficient biochemical characteristics and about 100 diverse mutations have been identified $[2,3]$. The most common clinical consequences of G6PD deficiency are neonatal jaundice and sporadic haemolytic crises caused by infections, certain drugs or, in the Mediterranean variant, by ingestion of fava beans or inhalation of their pollen $[1,4]$.

The study of G6PD deficiency in Iraq dates back to 1963 [5] when the first published study triggered a cascade of research on the problem in the country. The present study aimed to determine the epidemiological, clinical and laboratory profile of G6PD deficiency in Baghdad in the centre of Iraq and compare it with previously published data from Mosul in the north of the country. Unfortunately, similar published data from Basra, south of Baghdad, was unavailable for comparison.

\section{Methods}

The study was conducted on 156 under 5-year-olds with documented G6PD deficiency by G6PD enzyme essay. Data were collected over the period 1 January 2000 to 31 December 2006 from the records of patients admitted with a haemolytic episode to one of the 3 hospitals in Baghdad city (Al-Khadimyiah paediatric hospital, Al-Karama teaching hospital department of paediatrics and Al-Noor teaching hospital department of paediatrics).

Through a review of medical records, data concerning age, sex, clinical presentation, onset of haemolysis, past history of neonatal jaundice, family history of G6PD deficiency, laboratory results and final outcome were obtained. The above data were compared with those reported previously in Mosul city [6].

\section{Results}

Out of 156 patients recruited to the study, 97 (62.2\%) were males and 59 (37.8\%) were females, a male to female ratio of 1.6:1. The mean age was 2.8 (standard deviation 1.2) years. More than half the patients (58.3\%) were in the age group $1-4$ years.

The characteristics of the study patients are shown in Table 1. Past history of neonatal jaundice was recorded in $11.5 \%$ and a positive family history of G6PD deficiency in 19.2\%. Recurrent episodes of haemolysis were reported by $10.9 \%$ of patients. A majority of patients (69.2\%) had experienced haemolytic episodes within 1-3 days of exposure to precipitating agents (usually fava beans and to a lesser extent drugs such as trimethoprime-sulfamethoxazole or nalidixic acid. Clinically, symptoms and signs of dark colour urine and pallor were universal presenting symptoms (100\%), whereas jaundice was reported in $82.7 \%$ and hepatosplenomegaly in $56.4 \%$ of patients. Half the patients (52.6\%) had moderate anaemia $(5-7 \mathrm{~g} / \mathrm{dL})$.

Reticulocyte count and total white blood cell counts ranged from $4.5 \%$ to $19.6 \%$ and 4.9 to $25 \times 10^{9} / \mathrm{L}$ respectively. The range of total serum bilirubin (mainly indirect type) was $2.6-13.8 \mathrm{mg} / \mathrm{dL}$. Blood urea and serum creatinine ranged from 35 to $47 \mathrm{mg} / \mathrm{dL}$ and 0.7 to $1.1 \mathrm{mg} / \mathrm{dL}$ respectively.

All patients received blood transfusions in various amounts and were discharged within 2-4 days of hospitalization. No deaths were recorded.

\section{Discussion}

Iraq is situated within a region of a high frequency of G6PD deficiency genotype, with a carrier frequency in the population of $6.3 \%$ [7]. Studying the pattern of G6PD deficiency in the population is essential for a number of reasons: the increasing costs of health care associated with frequent hospitalizations [8]; the substantial morbidity in terms of psychosocial burden and disturbed family environment for parents coping with children with chronic illness [9]; and for planning preventive strategies [10].

A preponderance of males was noted in both the present study in Baghdad and the previous study in Mosul (1.6:1 and 3.4:1 respectively). The preponderance of females noted in some studies in other countries in the Eastern Mediterranean Region may be due to high rates of consanguinity, leading to increased numbers of homozygous females in addition to a high frequency of inactivation of the normal X chromosome in female heterozygotes, which leads to disturbances in the Hardy-Weinberg equilibrium. Moreover, the presence of an "enhanced" gene that makes the expression of G6PD deficiency more likely has been suggested $[11,12]$.

A past history of neonatal jaundice was found in similar proportions of children in this study in Baghdad (11.5\%) and the previous study in Mosul (14.8\%) [6]. Severe neonatal jaundice, particularly when it requires exchange transfusion, should alert paediatricians to the possibility of G6PD deficiency. Currently, most hospitals routinely test for G6PD when screening neonates before they are discharged from hospital [13].

A positive family history of G6PD deficiency was reported at a higher rate in the Baghdad (19.2\%) than in Mosul 


\begin{tabular}{|c|c|c|c|c|}
\hline \multirow[t]{2}{*}{ Variable } & \multicolumn{2}{|c|}{ Baghdad study ${ }^{\mathrm{a}}(n=156)$} & \multicolumn{2}{|c|}{ Mosul study $(n=88)$} \\
\hline & No. & $\%$ & No. & $\%$ \\
\hline \multicolumn{5}{|l|}{ Sex } \\
\hline Male & 97 & 62.2 & 68 & 77.3 \\
\hline Female & 59 & 37.8 & 20 & 22.7 \\
\hline Male:female (ratio ) & \multicolumn{2}{|c|}{$1.6: 1$} & \multicolumn{2}{|c|}{$3.4: 1$} \\
\hline \multicolumn{5}{|l|}{ Clinical history } \\
\hline Positive past history of neonatal jaundice & 18 & 11.5 & 13 & 14.8 \\
\hline Positive family history of G6PD deficiency & 30 & 19.2 & 12 & 13.6 \\
\hline Recurrent attacks of haemolysis & 17 & 10.9 & 8 & 9.1 \\
\hline \multicolumn{5}{|l|}{ Onset of haemolysis } \\
\hline Few hours & 10 & 6.4 & 4 & 4.5 \\
\hline 1-3 days & 108 & 69.2 & 67 & 76.1 \\
\hline 4-7 days & 38 & 24.4 & 17 & 19.3 \\
\hline \multicolumn{5}{|l|}{ Clinical presentation } \\
\hline Dark colour urine & 156 & 100.0 & 88 & 100.0 \\
\hline Pallor & 156 & 100.0 & 88 & 100.0 \\
\hline Jaundice & 129 & 82.7 & 69 & 78.4 \\
\hline Hepatosplenomegaly & 88 & 56.4 & 55 & 62.5 \\
\hline Fever & 59 & 37.8 & 39 & 44.3 \\
\hline Abdominal pain & 33 & 21.1 & 14 & 15.9 \\
\hline \multicolumn{5}{|l|}{ Haematological tests } \\
\hline \multicolumn{5}{|l|}{ Haemoglobin (g/dL) } \\
\hline$<5$ & 42 & 26.9 & 29 & 32.9 \\
\hline $5-7$ & 82 & 52.6 & 39 & 44.3 \\
\hline $7-9$ & 32 & 20.5 & 20 & 22.7 \\
\hline Reticulocyte count (\%) & \multicolumn{2}{|c|}{$4.5-19.6$} & \multicolumn{2}{|c|}{$3.0-25.0$} \\
\hline White blood cell count (/L) & \multicolumn{2}{|c|}{$4.9-25.0 \times 10^{9}$} & \multicolumn{2}{|c|}{$3.9-40.0 \times 10^{9}$} \\
\hline \multicolumn{5}{|l|}{ Biochemical tests } \\
\hline Total serum bilirubin (mainly indirect) (mg/ dL) & \multicolumn{2}{|c|}{$2.6-13.8$} & \multicolumn{2}{|c|}{$1.2-28.2$} \\
\hline Blood urea $(\mathrm{mg} / \mathrm{dL})$ & \multicolumn{2}{|c|}{$35-47$} & \multicolumn{2}{|c|}{ Normal } \\
\hline Serum creatinine $(\mathrm{mg} / \mathrm{dL})$ & \multicolumn{2}{|c|}{$0.7-1.1$} & \multicolumn{2}{|c|}{ Normal } \\
\hline \multicolumn{5}{|l|}{ Outcome } \\
\hline Recovery (days) & \multicolumn{2}{|c|}{$2-4$} & \multicolumn{2}{|c|}{$2-3$} \\
\hline Mortality rate (\%) & \multicolumn{2}{|c|}{0} & \multicolumn{2}{|c|}{0} \\
\hline
\end{tabular}

Sources: ${ }^{a}$ Present study; ${ }^{b}$ [6].

(13.6\%). This may be due to the observation that many patients are asymptomatic and unaware they are G6PD deficient unless they are investigated or exposed to an oxidizing agent.

A majority of patients in Baghdad (69.2\%) and Mosul (76.1\%) showed haemolysis within 1-3 days of exposure to precipitating agents. This is similar to what has been reported elsewhere [1416]. Recurrent haemolytic episodes were recorded in a slightly lower percentage of children in Baghdad (10.9\%) and Mosul (9.1\%). Prevention of further attacks needs awareness of patients and their families to the need to avoid exposure to oxidative stress.

Dark colour urine, pallor, jaundice and hepatosplenomegaly were the leading clinical presentations in both areas of Iraq. This observation is consistent with previous studies [14-16]. When liver function is normal, jaundice typically does not occur until more than $50 \%$ of erythrocytes have been haemolysed [17]. The size of the spleen and liver in both studies varied from just palpable to 3-4 cm below the costal margin.

Fever was documented in $37.8 \%$ of the patients in the Baghdad study compared with $44.3 \%$ in the Mosul study. Many individuals develop fever after the onset of infections such as urinary 
tract infection, enteric fever and chest infections. The mechanism linking infection and haemolysis is complex and poorly understood. However it has been suggested that during phagocytosis leukocytes damage erythrocytes in their vicinity by discharging reactive oxygen species. Moreover, certain infectious organisms, such as Plasmodium, Clostridium, Babesia and Bartonella spp., are directly toxic to red blood cells [18]. Recently, it was noted that a mild degree of G6PD deficiency (comparable to the human class III G6PD deficiencies) worsens erythrocyte dysfunction during sepsis. Increased erythrocyte rigidity and a tendency for haemolysis, together with alterations in the interaction between erythrocyte band 3 protein and spectrin, may contribute to the immunomodulatory effect of G6PD deficiency observed after major trauma and infection in humans [19] .Unfortunately, screening for infectious diseases was not done in either of the Iraqi studies.

Variable grades of anaemia, reticulocytosis and leukocytosis were noted in both studies. A higher rate of moderate anaemia $(5-7 \mathrm{~g} / \mathrm{dL})$ was found in Baghdad (52.6\%) than in Mosul (44.3\%). The oxidized and denaturated haemoglobin forms cross-links and precipitates intracellularly, forming red-cell inclusion bodies that are identified as Heinz bodies on supravital staining of peripheral blood smears. These inclusion bodies are removed in the spleen, leaving erythrocytes with a missing section of cytoplasm. These "bite cells" can be seen in the routine blood smear [1].
Although hyperbilirubinaemia, particularly of the unconjugated type, is the main criterion for the diagnosis of haemolytic anaemia, it is mild and selflimiting when liver function is normal [1]. In the Baghdad and Mosul studies, variable grades of hyperbilirubinaemia particularly the indirect type were seen (2.6-13.8 mg/dL and $1.2-28.2 \mathrm{mg} /$ $\mathrm{dL}$ respectively). The higher range of serum bilirubin in the Mosul study may be attributed to the preponderance of cases of severe neonatal jaundice necessitating ultimately phototherapy and/or exchange transfusion.

Renal function was preserved in patients in the Baghdad and Mosul studies, as manifested by nearly normal blood urea and serum creatinine levels. Azotaemia can complicate severe intravascular haemolysis and oliguria. Therefore, therapy must focus on maintaining a high urine output.

All patients in both studies showed uneventful recovery within 2-4 days of hospitalization after receiving various degrees of blood transfusion. No deaths were reported in either study. Deaths reported during acute haemolytic episodes are attributed to severe anaemia causing congestive heart failure, oliguric renal shutdown, malaria and hepatic encephalopathy [20-23].

The epidemiological, clinical and laboratory picture of G6PD deficiency was very similar in patients from Baghdad and Mosul cities. It has been observed that in areas with a high occurrence of red blood cell genetic abnormalities, such as sickle-cell gene, G6PD and $\alpha$ - and $\beta$-thalassaemias, various genes frequently coexist in the same population. Coinheritance of 2 or more abnormal genes in the same individual is frequently encountered, particularly in certain "closed" tribes in which consanguineous marriages are the norm. Such genetic interactions modify the clinical presentation of the disease state $[24,25]$.

In conclusion, the similar epidemiological, clinical and laboratory profile of G6PD deficiency in the middle and north of Iraq suggest genetic similarities in the G6PD variants and similar exposure to precipitating agents. Studies in the other parts of the country particularly the south would further elucidate the picture of G6PD deficiency in Iraq, and a national survey is needed to address the exact biochemical and epidemiological variants of G6PD deficiency. Further studies would also be useful to determine possible interactions between various abnormal red blood cell genotypes notably G6PD, thalassaemia and sickle cell haplotypes. Educational programmes are needed to increase public awareness about G6PD deficiency.

\section{Acknowledgements}

Great thanks are due to the administrators of the aforementioned hospitals in Baghdad for their kind help in accomplishing the study.

\section{References}

1. Beulter E. Glucose-6-phosphate dehydrogenase and other enzyme abnormalities. In: Beutler E et al., eds. William's haematology, 6th ed. New York, McGraw-Hill, 2001.

2. Beulter E. G6PD deficiency. Blood, 1994, 84:3613-3636.

3. Cappellini MD, Fiorelli G. Glucose-6-phosphate dehydrogenase deficiency. Lancet, 2008, 371:64-74.

4. Dors $\mathrm{N}$ et al. Glucose-6-fosfaatdehydrogenasedeficientie: klinische presentatie en uitlokkende factoren [Glucose-6phosphate dehydrogenase: clinical presentation and eliciting factors]. Nederlands Tijdschrift voor Geneeskunde, 2008, 152(18):1029-1033.
5. Taj El-Din S, Al-Samarrae A, Al-Abbosi A. Favism in Iraq. Journal of the Faculty of Medicine (Baghdad), 1963, 1:1-7.

6. Omar SK. Clinical profile of children with favism. Annals of the College of Medicine, Mosul, 1998, 24(1\&2):27-31.

7. Hilmi FA et al. Red cell glucose-6-phosphate dehydrogenase phenotypes in Iraq. Eastern Mediterranean Health Journal, 2002, 8(1):42-48.

8. Merenstien D, Egleston B, Diener-West M. Lengths of stay and costs associated with children's hospitals. Pediatrics, 2005, 115(4):839-844. 
9. Rao P, Pradhan PV, Shati H. Psycho-pathology and coping in parents of chronically ill children. Indian Journal of Pediatrics, 2004, 71(8):695-699.

10. Atwood K, Colditz GA, Kawachi I. From public health science to preventive policy: placing science in its social and political contexts. American Journal of Public Health, 1997, 87:1603-1606.

11. Abdulrazzaq YM et al. Diversity in expression of glucose-6phosphate dehydrogenase deficiency in females. Clinical Genetics, 1999; 55(1):13-19.

12. Warsy AS, El-Hazmi MAF. G6PD deficiency, distribution and variants in Saudi Arabia: an overview. Annals of Saudi Medicine. 2001, 21(3-4):174-177.

13. Iwai $\mathrm{K}$ et al. A rapid single-step screening method for glucose6-phosphate dehydrogenase deficiency in field application. Japanese Journal of Tropical Medicine and Hygiene, 2003, 31:93-97.

14. Verle P et al. Glucose-6-phosphate dehydrogenase deficiency in Northern Vietnam. Tropical Medicine and International Health, 2000, 5(3):203-206.

15. Grunfeld A. Acute hemolytic crisis in patients with G6PD deficiency: a case series. Prehospital and Disaster Medicine, 2001, 16(2):S33.

16. Laosombat $\mathrm{V}$ et al. Glucose-6-phosphate dehydrogenase variants associated with favism in Thai children. International Journal of Hematology, 2006, 83(2):139-143.

17. Edwards CQ. Anemia and the liver: hepatobiliary manifestations of anemia. Clinical Liver Diseases, 2002, 6:891-897.
18. Berkowitz FE. Hemolysis and infections: categories and mechanisms of their interrelationship. Reviews of Infectious Diseases. 1991, 13:1151-1162.

19. Spolarics Z et al. Red blood cell dysfunction in septic glucose-6-phosphate dehydrogenase-deficient mice. American Journal of Physiology. Heart and Circulatory Physiology, 2004, 286(6):H2118-H2126.

20. Sarkar S et al. Acute intravascular hemolysis in glucose-6-phosphate dehydrogenase deficiency. Annals of Tropical Pediatrics. 1993, 13(4):391-394.

21. Ali M et al. Acute viral hepatitis with severe hyperbilirubinemia and massive hemolysis in glucose-6-phosphate dehydrogenase deficiency. Journal of Clinical Gastroenterology, 2001, 32:461-462.

22. Balaka B et al. Insuffisance renale post-hemolytique chez I'enfant deficient en glucose-6-phosphate deshydrogenase au Centre Hospitalier Universitaire de Lome. [Post-hemolytic renal failure in children with glucose-6-phosphate dehydrogenase deficiency at the university hospital center in Lome.] Medicine Tropicale, 2003, 63(2):151-154.

23. Drout M, Gorgels AP, Bast A. Cardiac failure associated with G6PD deficiency. Circulation Research, 2003, 93(8):e75.

24. Awamy BH. Effect of G6PD deficiency on sickle cell disease in Saudi Arabia. Indian Journal of Pediatrics, 1992, 59(3):331-334.

25. El-Hazmi MAF et al. Genetic compounds-Hb S, thalassaemias and enzymopathies: spectrum of interactions. Journal of Tropical Pediatrics, 1994, 40(3):149-156.

\section{Genomic Resource Centre}

The World Health Organization (WHO) is one of several international organizations which have expressed concern about the widening knowledge and technology gap between the more developed and less developed countries, which could lead to the neglect of the health needs of low-income nations. WHO is therefore working to build international networks that involve researchers from all over the world, creating reliable, accessible information and knowledge-sharing tools specifically tailored for middle- to low-income countries. The Genomic Resource Centre (GRC). is an example of such a tool.

The Human Genetics Programme has created a comprehensive Internet-based resource on genomics. The GRC's primary mandate is to consolidate information from a variety of sources and provide links through easily accessible frameworks.This is the first website of its kind dedicated to providing reliable information on genomics and health to developing countries. The mission of the GRC is to enhance the transfer of genomic information, to encourage global networks, to foster informed dialogue, and to improve health services in genetics, especially in low to middleincome countries.

Further information on this resource is available at: http://www.who.int/genomics/en/ 